University of Nebraska - Lincoln

DigitalCommons@University of Nebraska - Lincoln

2008

\title{
A New Fluorinated Polymer Having Two Connected Rings in the Main Chain: Synthesis and Characterization of Fluorinated Poly(1,3-cyclohexadiene)
}

Tianzi Huang

Jamie M. Messman

Jimmy W. Mays

Follow this and additional works at: https://digitalcommons.unl.edu/usdoepub

Part of the Bioresource and Agricultural Engineering Commons

Huang, Tianzi; Messman, Jamie M.; and Mays, Jimmy W., "A New Fluorinated Polymer Having Two Connected Rings in the Main Chain: Synthesis and Characterization of Fluorinated Poly(1,3-cyclohexadiene)" (2008). US Department of Energy Publications. 74.

https://digitalcommons.unl.edu/usdoepub/74

This Article is brought to you for free and open access by the U.S. Department of Energy at DigitalCommons@University of Nebraska - Lincoln. It has been accepted for inclusion in US Department of Energy Publications by an authorized administrator of DigitalCommons@University of Nebraska - Lincoln. 


\section{A New Fluorinated Polymer Having Two Connected Rings in the Main Chain: Synthesis and Characterization of Fluorinated Poly(1,3-cyclohexadiene)}

\author{
Tianzi Huang, ${ }^{\dagger}$ Jamie M. Messman,, and \\ Jimmy W. Mays*, ${ }^{*}$,
}

Department of Chemistry, University of Tennessee, Knoxville, Tennessee 37996, and Chemical Sciences Division and Center for Nanophase Materials Sciences, Oak Ridge National Laboratory, Oak Ridge, Tennessee 37831

\section{Received August 9, 2007}

Revised Manuscript Received October 30, 2007

The high electronegativity and small size of the fluorine atom and the high stability of $\mathrm{C}-\mathrm{F}$ bonds impart interesting properties and applications to fluorine containing polymers. The unique properties of fluoropolymers include high thermal stability, improved chemical resistance, low surface energies, low coefficients of friction, and low dielectric constants. ${ }^{1}$ Applications of fluorinated polymers include use as noncorrosive materials, polymer processing aids, chemically resistant and antifouling coatings, as well as interlayer dielectrics. Fluorine-containing polymers can be directly synthesized via polymerization of fluorine-containing monomers or by post-polymerization modification. ${ }^{2}$ The latter method can be used to attach fluorinated species, such as perfluoroalkyl groups, onto conventional polymer chains, thereby imparting properties of fluorinecontaining polymers into conventional polymers and widening their range of potential applications.

Fluorination of polydienes by different mechanisms has been previously investigated by several research groups. For instance, radical grafting of perfluoroalkyl iodides ${ }^{3}$ and fluorinated thiols ${ }^{4}$ has been successfully employed. Additionally, hydrosilylation of perfluoroalkylsilanes ${ }^{5}$ and fluorocarbene additions ${ }^{6}$ have been reported. Addition of difluorocarbene to polydienes yields cyclopropanated materials, which retains the polydiene stereochemistry due to the singlet ground-state electronic structure of difluorocarbene. ${ }^{6}$ Hillmyer et al. recently reported a mild, selective, and quantitative fluorination of polydienes by in situ generated difluorocarbenes (: $\left.\mathrm{CF}_{2}\right)$ from thermolysis of hexafluoropropylene oxide (HFPO), a commercially available compound. ${ }^{7}$ Insertion of : $\mathrm{CF}_{2}$ into the double bonds of polyisoprene and polybutadiene was shown to be quantitative and free of side reactions such as chain scission and coupling. Fluorination significantly altered the physical properties of these polydienes, providing solubility in supercritical $\mathrm{CO}_{2}$ and greatly enhancing $T_{\mathrm{g}}{ }^{7,8}$ Furthermore, selective fluorination of polyisoprene and polybutadiene in block copolymers using $\mathrm{CF}_{2}$ was also demonstrated. ${ }^{9}$ The Flory-Huggins interaction parameter between the different blocks increased upon fluorination, and therefore strong segregation behavior was observed. ${ }^{9}$

In this paper, we report the preparation and characterization of PCHD samples with high 1,4-structure ( $95 \mathrm{~mol} \%)$ and mixed 1,4-/1,2- ( 50/50) structures (by $\left.{ }^{1} \mathrm{H} \mathrm{NMR}^{13}\right)$ via anionic polymerization and the subsequent fluorination of PCHD with

\footnotetext{
* To whom correspondence should be addressed. E-mail: jimmymays@ utk.edu.

Department of Chemistry, University of Tennessee.

$\leftarrow$ Chemical Sciences Division and Center for Nanophase Materials Sciences, Oak Ridge National Laboratory.
}

Scheme 1. Synthesis of Fluorinated Poly(1,3-cyclohexadiene) (PCHD).
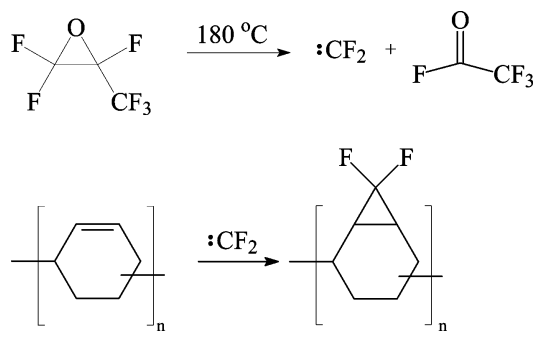

in situ generated : $\mathrm{CF}_{2}$. Because of its unique six-membered ring structure, PCHD is considerably less flexible than other polydienes. This results in higher $T_{\mathrm{g}} \mathrm{s}$, reduced solubility in common solvents, and even partial crystallinity. ${ }^{10}$ Although 1,3-cyclohexadiene has been polymerized via different mechanisms, only in recent years has it been possible to create PCHD chains with controlled molecular weight and low polydispersity via anionic polymerization. In order to facilitate controlled polymerization, 1,4-diazabicyclo[2.2.2] octane (DABCO) ${ }^{11}$ and $N, N, N^{\prime}, N^{\prime}$-tetramethylethylenediamine (TMEDA) ${ }^{12}$ are used as additives to minimize chain transfer and termination. The use of these additives alters the microstructure of PCHD, resulting in PCHDs of high 1,4-structure (95/5) or 1,4-/1,2-mixed structures (50/ 50) depending on the additive and its concentration. To this end, the physical properties of PCHD can be tailored through microstructural manipulation. ${ }^{13}$ Fluorination of PCHD with : $\mathrm{CF}_{2}$ yields polymeric materials with a unique structure: a bicyclic moiety where a three-membered ring is fused to a six-membered ring in each repeat unit on the polymer main chain. Unique, structurally related properties have been studied as discussed below, and novel applications are anticipated for these materials, such as use in alternative fuel cell membranes.Three linear PCHD samples with different molecular weights (5000 to 19700 $\mathrm{g} / \mathrm{mol}$ ) and microstructures (samples A and B for high 1,4structure; sample $\mathrm{C}$ for 50/50 mixed 1,4-/1,2-structure) were fluorinated. The addition of $: \mathrm{CF}_{2}$ to the PCHD double bonds was confirmed by NMR, FT-IR and elemental analysis (Supporting Information). No evidence for rearrangements is apparent from these data. Molecular weight and molecular weight distribution before and after fluorination were characterized by size exclusion chromatography (SEC), which was calibrated using polystyrene standards. The degree of fluorination was calculated based on the intensities of olefinic protons $(5.5-5.8$ $\mathrm{ppm})$ with respect to saturated hydrocarbon groups $(0.8-2.5$ ppm) of PCHD. The SEC and ${ }^{1} \mathrm{H}$ NMR characterization results of samples before and after fluorination are summarized in Table 1.

Purified benzene was chosen as the solvent since the PCHD and fluorinated PCHD samples are soluble or partially soluble in benzene at room temperature, and they are expected to form a homogeneous reaction mixture throughout the reaction at high temperature. The Parr reactor and reactants except HFPO were degassed twice under low temperature and high vacuum to avoid air and moisture which could cause side reactions at the experimental temperature $\left(180^{\circ} \mathrm{C}\right)$. HFPO was transferred into the reactor from a tank with a regulator and the mass of HFPO transferred was monitored using an analytical balance.

Various reaction conditions were investigated to study how tunable factors, such as concentration of inhibitor, concentration of the reactants, reaction time, etc., affect the efficiency of 
Table 1. Synthesis and Characteristics of Fluorinated Poly(1,3-cyclohexadiene $)^{a}$

\begin{tabular}{|c|c|c|c|c|c|c|c|c|c|c|c|}
\hline sample ${ }^{b}$ & $\begin{array}{c}\mathrm{MW} \\
(\mathrm{g} / \mathrm{mol}) / \mathrm{PDI}^{c}\end{array}$ & $\begin{array}{c}\text { HFPO } \\
(\mathrm{g} / \mathrm{L})\end{array}$ & $R^{d}$ & {$[\mathrm{BHT}]_{0}^{e}$} & $\begin{array}{l}\text { wt } \% \\
\text { BHT }^{f}\end{array}$ & $\begin{array}{c}\text { reacn } \\
\text { time }(\mathrm{h})\end{array}$ & $\mathrm{F}^{g}$ & $\begin{array}{c}\text { onset } \\
T_{\text {decomp }}\left({ }^{\circ} \mathrm{C}\right)\end{array}$ & $\begin{array}{l}\text { pyrol resid } \\
\text { (wt \%) }\end{array}$ & $\begin{array}{c}T_{\mathrm{g}} \\
\left({ }^{\circ} \mathrm{C}\right)\end{array}$ & $\begin{array}{l}\Delta T_{\mathrm{g}} \\
\left({ }^{\circ} \mathrm{C}\right)\end{array}$ \\
\hline A & $16200 / 1.12$ & & & & & & & 328 & 0 & 120 & \\
\hline FA-1 & $19100 / 1.23$ & 20 & 10 & 6.7 & 1.0 & 4 & 53 & 353 & 4.8 & 171 & 51 \\
\hline FA-2 & $20700 / 1.24$ & 41 & 20 & 67 & 10 & 2 & 74 & 360 & 12.4 & 174 & 54 \\
\hline FA-3 & $20100 / 1.26$ & 42 & 20 & 67 & 10 & 4 & 86 & 364 & 16.7 & 197 & 77 \\
\hline FA-4 & $20300 / 1.24$ & 40 & 20 & 67 & 10 & 6 & $91^{h}$ & 362 & 18.3 & 199 & 79 \\
\hline FA-5 & $20500 / 1.26$ & 38 & 18 & 67 & 10 & 8 & 84 & 360 & 15.8 & 198 & 78 \\
\hline FA-6 & $20200 / 1.25$ & 58 & 9 & 67 & 4.7 & 6 & 86 & 363 & 16.5 & 197 & 77 \\
\hline B & $5000 / 1.26$ & & & & & & & 332 & 0 & 98 & \\
\hline FB & $8850 / 1.27$ & 51 & 12 & 67 & 5.0 & 6 & 95 & 369 & 15.9 & 177 & 79 \\
\hline $\mathrm{C}$ & $19700 / 1.12$ & & & & & & & 336 & 0 & 138 & \\
\hline FC-1 & 15 400/1.12 & 42 & 20 & 67 & 10 & 6 & 71 & 361 & 10.7 & 229 & 91 \\
\hline FC-2 & $14500 / 1.12$ & 58 & 11 & 67 & 6.8 & 15 & 73 & 363 & 10.9 & 235 & 97 \\
\hline
\end{tabular}

${ }^{a} \mathrm{MW}=$ number-average molecular weight, $M_{\mathrm{n}}$, determined by conventional calibration using narrow polystyrene standards; HFPO = hexafluoropropylene oxide; $\mathrm{BHT}=2,6$-di-tert-butyl-4-methylphenol; $T_{\mathrm{g}}=$ glass transition temperature determined by differential scanning calorimetry. ${ }^{b}$ With regard to the "sample" column, A, B, and C indicate parent or precursor PCHD materials, respectively. The prefix F (e.g., FA-1) indicates that the PCHD has been fluorinated by in situ generated difluorocarbenes. The suffix (e.g., FA-1), when used, identifies unique reaction conditions used in the fluorination process. ${ }^{c}$ Polydispersity index. ${ }^{d}[\mathrm{HFPO}] /[\mathrm{C}=\mathrm{C}]$, molar ratio $(\mathrm{mol} / \mathrm{mol}) .{ }^{e}$ In mg per $100 \mathrm{~mL}$ solvent. ${ }^{f}$ BHT/PCHD weight ratio. ${ }^{g}$ Degree of fluorination (mol $\%$ ) by ${ }^{1} \mathrm{H}$ NMR spectroscopy. ${ }^{h}$ Anal. Found: C, 65.72; H, 6.32; F, 27.94. Calculated degree of fluorination $93 \%$.

fluorination and the extent of side reactions. 2,6-Di-tert-butyl4-methylphenol (BHT) was used to prevent radical coupling of double bonds of PCHD, which would cause undesirable bimodal molecular weight distributions. Optimal BHT concentrations were determined as larger concentrations of BHT caused reduced molecular weight and broadened molecular weight distributions, as well as unwanted coloring. At a BHT concentration of 67 $\mathrm{mg}$ per $100 \mathrm{~mL}$ solvent, no indication of bimodal molecular weight distributions was observed in SEC. Excess HFPO $(\sim 10-$ 20 fold) was used in all reaction formulations. It was found that HFPO must attain minimal concentrations $(\sim 40 \mathrm{~g} / \mathrm{L}, 40$ grams HFPO in a $1 \mathrm{~L}$ reactor) in order to achieve the highest degrees of fluorination.

Fluorination proceeded relatively quickly at the beginning of the reaction as nearly $75 \%$ of the double bonds were fluorinated within $2 \mathrm{~h}$ (see entry FA-2, Table 1). Fluorination of higher molecular weight PCHD (MW > $16 \mathrm{~kg} / \mathrm{mol}$ ) was maximized in 4-6 h (see entries FA-3 and FA-4, Table 1), while longer reaction times did not increase the degree of fluorination, but rather produced more insoluble materials and a deeper color in the mixture were observed (see entries FA-5 and FC-2, Table 1). The thermolysis of HFPO also generates undesired materials, including insoluble polydifluoromethylene (PTFE). ${ }^{14}$

The nature of the polymer chain strongly affects the fluorination reaction. Fluorination of low molecular weight PCHD reached higher degrees of fluorination because of increased solubility compared to higher molecular weight PCHD (sample FB, Table 1). Similarly, PCHD microstructure appears to influence the degree of fluorination. We observed that fluorination of high 1,4-structured PCHD was greater than that of 50/ 50 mixed 1,4-/1,2-PCHD also due to its enhanced solubility before and after fluorination.

Molecular weight distribution broadening was observed in all samples having high 1,4-structure. It is postulated that this broadening could be simply caused by chain coupling and chain scission during fluorination at high temperatures. It is plausible that side reactions, such as the formation of byproducts from decomposing HFPO,${ }^{14}$ and the rearrangement of the resulting difluorocyclopropanated three-membered ring on the sixmembered ring structure along the polymer main chain triggered the broadening. ${ }^{15}$

Interestingly, the $\mathrm{C}$ series of materials (entries FC-1 and FC2, Table 1) shows an apparent decrease in molecular weight upon fluorination, but there is no broadening of the PDI as in the $\mathrm{A}$ and $\mathrm{B}$ series materials. We believe that the apparent molecular weight decrease is caused by a reduction of hydrodynamic volume upon fluorination resulting in higher elution volume. That the change in elution volume is caused by a reduction in hydrodynamic volume rather than degradation is supported by the lack of PDI broadening. The mixed microstructure (50/50 1,4-/1,2-) in the $\mathrm{C}$ series materials hinders fluorination due to comparatively lower solubility than high 1,4materials. Subsequently, this results in a low level of chain coupling or chain scission and the PDI remains unchanged.

Thermal analysis (Table 1) indicated that fluorinated PCHDs have greater thermal stability as compared to their precursors, which is seen by increased temperatures for onset of decomposition $\left(\sim 30{ }^{\circ} \mathrm{C}\right.$ enhancement in analogous series). Unlike pure PCHD which decomposed $100 \%$, the fluorinated sample produced graphite-like residues. It was observed that upon pyrolysis, the residual mass was proportional to the degree of fluorination with little or no influence of the polymer microstructure. Fluorination also dramatically increased the glass transition temperature $\left(\Delta T_{\mathrm{g}}=+97{ }^{\circ} \mathrm{C}, \mathrm{FC}-2\right)$, where $\Delta T_{\mathrm{g}}$ increases sharply at moderate degrees of fluorination $(50<F$ $<75)$ and appears to reach a maximum $\left(\Delta T_{\mathrm{g}} \sim 80 \mathrm{C}\right.$ for $86<$ $F<95)$ at high degrees of fluorination. Moreover, microstructure appears to play a more significant role regarding the enhancement of $T_{\mathrm{g}}$. For example, sample FC-2 displays the greatest $T_{\mathrm{g}}$ enhancement with only $73 \%$ fluorination. Fluorinated PCHD has the highest $T_{\mathrm{g}}$ among all fluorinated polydienes: $T_{\mathrm{g}}$ $\mathrm{s}$ of fluorinated polybutadiene and polyisoprene obtained via the same fluorination method are only -1 and $+43{ }^{\circ} \mathrm{C}$, respectively. ${ }^{7}$

As with other polydienes, the double bonds in PCHD are sensitive to physically and chemically induced degradation, which could limit its applications. Fluorination reduces the level of unsaturation and widens the range of potential applications of PCHD by improving its thermal and chemical stability. Surface properties, although not investigated, should also be impacted. We are presently synthesizing and characterizing fluorinated and sulfonated copolymers based upon PCHD, which have potential utility as fuel cell proton exchange membranes.

Acknowledgment. The authors acknowledge the financial support from the U.S. Army Research Office (R011024130). A portion of this research was conducted at the Center for Nanophase Materials Sciences, which is sponsored at Oak Ridge National Laboratory by the Division of Scientific User Facilities, U.S. Department of Energy. We also thank Professor M. A. 
Hillmyer and Dr. D. A. Davidock for their helpful discussions and Mr. T. Malmgren for his technical support with thermal analysis.

Supporting Information Available: Text giving the details of the fluorination reaction and figures showing typical NMR spectra $\left({ }^{1} \mathrm{H}\right.$ and $\left.{ }^{19} \mathrm{~F}\right)$, FT-IR spectra, TGA results, and GPC chromatograms. This material is available free of charge via the Internet at http:// pubs.acs.org.

\section{References and Notes}

(1) Hougham, G.; Cassidy, P. E.; Johns, K.; Davidson, T. Fluoropolymers 2 Properties; Kluwer Academic/Plenum Publishers: New York, 1999.

(2) (a) Reisinger, J. J.; Hillmyer, M. A. Prog. Polym. Sci. 2002, 27, 9711005. (b) Ameduri, B.; Boutevin, B. Well-Architectured Fluoropolymers: Synthesis. Properties and Applications; Elsevier: New York 2004. (c) Imae, T. Curr. Opin. Colloid Interface Sci. 2003, 8, 307314

(3) (a) May, D. D. US Patent 5,681,902, 1997. (b) Ren, Y.; Lodge, T. P.; Hillmyer, M. A. Macromolecules 2001, 34, 4780-4787.

(4) (a) Boutevin, B.; Hervaud, Y.; Nouiri, M. Eur. Polym. J. 1990, 26, 877-882. (b) Ameduri, B.; Boutevin, B.; Nouiri, M. J. Polym. Sci., Part A: Polym. Chem. 1993, 31, 2069-2080.

(5) (a) Hwang, S. S.; Ober, C. K.; Perutz, S.; Iyengar, D. R.; Schneggenburger, L. A.; Kramer, E. J. Polymer 1995, 36, 1321-1325. (b) Samuel, J. D. J. S.; Dhamodharan, R.; Ober, C. K. J. Polym. Sci., Part A: Polym. Chem. 2000, 38, 1179-1183.

(6) (a) Osteraas, A. J.; Olsen, D. A. Nature (London) 1969, 1140-1141. (b) Thomsen, M. W.; Stephanie, A. K.; Horenkamp, E. C.; Heidig,
K. S. Macromolecules 1989, 22, 481-483. (c) Siddiqui, S.; Cais, R. E. Macromolecules 1986, 19, 595-603.

(7) Ren, Y.; Lodge, T. P.; Hillmyer, M. A. J. Am. Chem. Soc. 1998 , $120,6830-6831$

(8) McHugh, M. A.; Park, I.-H.; Reisinger, J. J.; Ren, Y.; Lodge, T. P.; Hillmyer, M. A. Macromolecules 2002, 35, 4653-4657.

(9) (a) Ren, Y.; Lodge, T. P.; Hillmyer, M. A. Macromolecules 2000, 33, 866-876. (b) Ren, Y.; Lodge, T. P.; Hillmyer, M. A. Macromolecules 2002, 35, 3889-3894. (c) Davidock, D. A.; Hillmyer, M. A.; Lodge, T. P. Macromolecules 2004, 37, 397-407. (d) Davidock, D. A.; Hillmyer, M. A.; Lodge, T. P. Macromolecules 2003, 36, $4682-4685$.

(10) Quirk, R. P.; You, F.; Zhu, L.; Cheng, S. Z. D. Macromol. Chem. Phys. 2003, 204, 755-761.

(11) (a) Hong, K.; Mays, J. W. Macromolecules 2001, 34, 782-786. (b) Hong, K.; Wan, Y.; Mays, J. W. Macromolecules 2001, 34, 24822487. (c) Hong, K.; Mays, J. W. Macromolecules 2001, 34, 35403547.

(12) (a) Natori, I. Macromolecules 1997, 30, 3696-3697. (b) Natori, I Inoue, S. Macromolecules 1998, 31, 982-987. (c) Williamson, D. T.; Elman, J. F.; Phillip, H.; Pasquale, A. J.; Long, T. E. Macromolecules 2001, 34, 2108-2114.

(13) Natori, I.; Imaizumi, K.; Yamagishi, H.; Kazunori, M. J. Polym. Sci., Part B: Polym. Phys. 1998, 36, 1657-1668.

(14) Sargeant, P. B. J. Org. Chem. 1970, 35, 678-682.

(15) Dailey, W. P.; Ralli, P.; Wasserman, D.; Lemal, D. M. J. Org. Chem. 1989, 54, 5516-5522.

MA0718043 